\title{
Medical ethics in laboratory medicine: A review, with an oath for pathologists
}

\begin{abstract}
The basic tenets of medical ethics are: autonomy of the patient, beneficence, non-maleficence and justice. These are usually interpreted in the light of the practice of clinical medicine but also apply to pathology and laboratory medicine, a field in which there is often no direct patient contact. We wished to evaluate these basic tenets of medical ethics with respect to laboratory medicine and to provide insights into some of the issues that laboratory physicians, in routine practice and in academia, face on a regular basis. This was done by using the published literature related to the topic of medical ethics, with a special focus on laboratory medicine, as well as the authors' interpretations and opinions, based on their experience. We conclude that the idea of autonomy of the patient or research participant is pertinent with respect to specimens, autopsies and in legal issues such as consent for publication in the media and social media. Beneficence is relevant with respect to laboratory values in reports, financial issues and in research and education. The concept of non-maleficence is important from the point of view of doing no harm, communication with patients and colleagues, reducing/containing error and misdiagnosis in medicine, screening for disease and in over diagnosis. Justice is applicable to issues of distribution of resources and manpower, and their equitable usage. Many of the tenets, however, need to be interpreted in the light of local laws and customs which differ across the world. We conclude with an Oath for pathologists and laboratory physicians.
\end{abstract}

Key words: medical ethics, misconduct, autonomy, beneficence, non-maleficence, justice, informed consent, medical research, oaths

\section{Introduction}

The significance of laboratory medicine is seen from the fact that $66 \%$ of clinical decisions were based on laboratory tests as shown by a recent study (1). Laboratory investigations also form an important component of biomedical research. Though the principles of medical ethics-autonomy, beneficence,

\footnotetext{
Authors: Swarupa Bhagwat (swarupabhagwat@kem.edu), Department of Transfusion Medicine, Seth GS Medical College and King Edward Memorial Hospital, Parel, Mumbai 400012 INDIA; Sanjay A Pai (corresponding author - sanjayapai@gmail.com), Department of Pathology and Laboratory Medicine, Columbia Asia Referral Hospital, Malleswaram, Bengaluru, 560055 INDIA.

To cite: Bhagwat S, Pai SA. Medical ethics in laboratory medicine: A review, with an oath for pathologists. Indian J Med Ethics. 2020 Jan-Mar;5(1)NS: 39-45. DOI: 10.20529/IJME.2020.002.

Published online on January 7, 2020.

Manuscript Editor:Vijayaprasad Gopichandran

Peer reviewers: Two anonymous reviewers

OIndian Journal of Medical Ethics 2020
}

non-maleficence and justice (2), are thought of largely in the context of clinician-patient interaction, they also include the pathologist-patient interaction. Baron has pointed out that the pathologist's ethical responsibilities extend well beyond the primary patient, and also include responsibilities to other patients, the referring physician, colleagues and staff, students, research subjects and animals, and the public (3).

Ethical issues related to laboratory medicine are not as commonly addressed as those in other spheres of medicine (4-8). This is probably because of the lack of direct contact of pathologists with patients. Issues unique to laboratory medicine include the use of residual samples for research, autopsies and the use of microscopic images.

The fundamental bioethical principles and the core virtues of honesty, integrity and reliability must be practised by a pathologist to safeguard the health as well as the rights of patients and research participants (7). It is obvious of course, that these principles of ethics are not mutually exclusive; some concepts (eg beneficence and non-maleficence) overlap. On occasion, one principle may conflict with the other the physician/pathologist, then, has to take a measured decision, after considering the possible harms versus the expected benefits of the decision taken in the interest of the patient (4).

Wijeratne and Benatar add that certain virtues such as compassion, discernment, trustworthiness, integrity and conscientiousness (5) are essential in the quest to achieve the high standards that good medical and laboratory practice must reach.

Despite these commonalities, there are apt to be differences between nations - sometimes significant - based on their history, political beliefs, economic and socio-cultural differences and mores, as well as those on the medico-legal front.

We discuss the basic tenets of medical ethics as applied to laboratory medicine.

\section{Autonomy of the patient /research participant}

Autonomy is the right to decide for oneself. Informed consent is the expression of this principle (2).

Laboratory tests require the patient/ research participant to undergo those investigations voluntarily. Implied consent is a consent which is not expressly granted by a person, but is implicitly granted by a person's actions and the circumstances of the situation. Implied consent is usually considered sufficient for most investigations as the patient presents himself/herself voluntarily to the laboratory. An exception to this is in HIV testing, where, as per WHO guidelines, written consent and counselling is essential prior to testing (9). 


\section{Autonomy and research samples}

A research project which involves collection of body specimens also requires informed consent of the research participant. This consent must clearly explain the purpose of the study as well as benefits and harms of participating in the research study (4). Approval from the Ethics Committee (EC) is necessary for all such studies. However, some issues arise after the completion of the study.

Can research be performed on the residual samples? Should the research be restricted to the disease that the patient has had? Or can it be used for research on other diseases? Does the biological material belong to the patient once it is removed from the body? The ownership of the paraffin blocks (and indeed, any biological material) is among the trickier and more contentious of ethical issues in the laboratory (10-22). Ideally, any research on the tissue samples should be done after taking the informed consent of the patient who owns the tissue, and/ or after obtaining approval from the EC, under the existing Indian laws.

If the patient (or the EC) denies permission for the storage of his or her tissue for research purposes, that decision must be respected. It goes without saying that confidentiality must always be maintained. The pathology laboratory thus plays the role of guardian, rather than proprietor, of stored body samples $(12,17,21)$.

There is much literature on the perspectives of those who believe that patient consent is essential before the scientist uses surplus material, and those who believe that it is not required $(19,20)$.

van Diest argues that the time and expense involved in getting repeat consent would be better spent in research (19). The excess material must be used to benefit science. He adds this can be done, provided confidentiality is maintained and all of the excess sample is not used up (in the eventuality that the patient may need it in the future). He adds that the principle of solidarity (ie helping others) is of greater importance than the right of self-determination (of patients deciding what needs to be done with their own excess tissue). On the other hand, Savulescu's stance is that consent is a must to maintain confidentiality as well as patient autonomy. He also believes that seeking consent would help build public confidence in scientific research and act as a check against the abuse or misuse of samples (20).

However, it is often not practical to contact patients years after their diagnosis. In addition, contacting a family long after a medical event may bring back painful memories of the suffering of a loved one - thus not only violating medical ethics but also common sense and humanity (22).

We believe in the principle of solidarity (19) or altruism. Today, we benefit from the largesse of research participants of the past (albeit involuntarily, and often without their consent). We owe it to the next generation to contribute our residual biological samples for future use. Since no harm can come to the individuals concerned (as there is no further invasive procedure), it is exigent on us to do so.

One way of tackling this issue is to consider seeking a broad consent which may be applicable in future, provided an EC permission is taken as well, to act as an appropriate check. Furness and Nicholson suggest, based on a study with opinions from patients, that it may be more practical to assume implied consent in most cases and to avoid using tissue only from those who specifically record their objections (22).

\section{Autonomy and autopsies}

Medico-legal autopsies do not require consent from family members. In clinical autopsies, consent from the family is mandatory. Because the autopsy is an invaluable teaching tool and its benefits could be passed on to future generations of patients and their doctors, one can easily make the case that autopsies should be made compulsory in many cases. This would be consistent with a Cartesian approach, which posits that because the body is no longer alive, thinking has stopped and the body is merely an object. However, sociocultural values predominate and it is the practice to follow the wishes of the relatives of the deceased (23). The family must be informed, and consent taken, about tissues being retained for academic and diagnostic purposes. That autopsy rates have declined is in itself a serious issue (24). One could argue that by the act of not promoting autopsies, physicians and pathologists are doing a disservice to science, to learning and to society and by implication, are behaving unscientifically.

Ethical issues regarding autopsy and organ retention have achieved great importance in the UK, and possibly in other countries, after the Alder-Hey episode (where children's organs were removed from the body and retained by the pathologist, without parental consent), early in this century (25).

\section{Autonomy and legal issues}

Healthcare providers must keep a patient's personal health information private unless directed by a court of law to release the information (26), or if it is a notifiable disease

Care should be taken not to discuss the test results in public places such as the cafe or elevators. Disclosure of certain reports may have serious personal and social consequences in the form of psychological trauma and social stigma, eg HIV testing, paternity testing, testing for genetic disorders and for drugs of abuse. Adequate counselling is required before the results are revealed. The results of genomic and DNA testing should be revealed only to the patient and the attending physician. The information must be revealed to parents when the patient is a minor. In research settings, confidentiality of laboratory results of the research participants should be ensured by maintaining anonymity.

While all journals agree that EC approval is essential for experimental studies and most journals desire patient consent for case reports, editors are often flexible about the latter, if patient consent is not possible due to logistic reasons. In fact, $B M J$ states that "Images - such as ....pathology slides...may be 
used without consent so long as they are anonymised ........" (27). Socio-cultural differences may also mean that the manner of ethics approval may be non-uniform among nations and this can further cloud the issue.

This, to us, echoes what Tranberg et al, and we, believe in - that patient consent is not necessary for the majority of images used for teaching and research, provided confidentiality is maintained (28).

The ease with which images can be disseminated, and the easy availability of the images to the physician and the public makes it crucial to take great care while using social media such as Facebook, Instagram and WhatsApp. Common sense and the principles of privacy are sufficient to address this. As there is no formal peer review system, unscientific information may be placed in cyberspace. Even if the post is taken down, it is likely that some files will remain on some sites, in their uncorrected versions (29). Crane and Gardner recommend that patient-specific data must be modified if it does not alter the context of the message being transmitted (29). They point out that generations of textbooks have carried images for educational purposes and conclude that the benefits of sharing images outweigh the risks.

\section{Beneficence}

Healthcare providers have a duty to be of benefit to the patient as well as to take positive steps to prevent harm.

\section{Beneficence and laboratory reports}

Beneficence implies that the laboratory physician has to be proactive and offer medical advice that extends beyond the mere act of diagnosis. Thus, a report must be appropriately worded and may recommend the taking of a second opinion Failure to inform a critical value could violate the principle of Primum non nocere.

\section{Beneficence and financial issues}

"Cuts" or fee-splitting by pathologists with physicians who refer patients to them are a common problem in India and probably elsewhere. Kickbacks are unethical and there should be no place for such a practice in any ethical health system. Feesharing between physicians only results in the patient ending up paying more. Thus, the concept of beneficence also overlaps with the idea of non-maleficence.

\section{Beneficence and research and education}

Research and teaching must also be seen through this ethics lens. It behoves all physicians to have an inquiring mind and to publish the fruits of their research, so that society benefits. This research must be published only in legitimate scientific journals; predatory journals (pseudojournals) often stoop to unethical practices. Because these journals are often not indexed in standard indexing bases, the data - often on patients or animals who have undergone potentially dangerous procedures - is lost to the scientific world $(30,31)$.
Failure to publish a paper when a researcher is in the know of an important finding, even if it is a negative finding, is unethical because it could lead to a waste of resources and time and also potentially puts other patients at risk, if another researcher decides to pursue the same hypothesis subsequently. Similarly, we believe that it is a professional obligation for pathologists/ physicians to teach students, colleagues, and the public. After all, the word "doctor" is derived from the Latin word docere, to teach.

\section{Non-maleficence}

This is the principle of Primum non nocere. No intentional harm or injury should come to the patient or research participant either through acts of commission or omission.

\section{Non-maleficence and communication}

Good communication between the pathologist and clinician is essential for patient safety (32). Direct communication between pathologist and patient is rather limited. Again, local practices vary and in the private sector, at least in India, the pathologist is often the first person the patient communicates with, at the time of collecting the laboratory report. A recent report on this subject raises the issue of a fee for service for a patient-pathologist meeting (33), with the editorial that such an act would be unprofessional. That financial considerations may adversely influence the practice of anatomic pathology have also been raised by Murphy (34).

\section{Non-maleficence and error in medicine}

Because of the complex, multistep nature of laboratory medicine, occasional errors are inevitable. How must these errors be dealt with, and who must the error disclosure be made to? The topic of error in medicine - both, in general, as well specifically in laboratory medicine - has been addressed now for the past two decades. There have been specific references to error in medicine, ever since the report by the Institute of Medicine (now known as the National Academy of Medicine) in 1999 (35). The initial report, has been followed in 2015, with a report which dealt with error in diagnosis (36). Error in pathology has been the subject of research in the recent past (37-40). In one study of laboratory directors, while most admitted to having made errors and having admitted them to their clinical colleagues, very few disclosed them to patients (37).

Whereas, ideally, the pathologist must disclose the error to the patient, the practice is generally for the treating physician to do so. There are unresolved issues, which cloud the matter. The exact definition of error itself - as interpreted by pathologists is sometimes nebulous (39). Pathologists also believe that many patients - as well as physicians - may not be in a position to understand the context and the mechanics of the medical error.

Lack of training in communicating with patients - and of course, the fact that pathologists often do not interact with their patients and hence are unable to build a patient-doctor relationship only makes the issue more complex (40). Regional practices also add to the complexity of the issue. 
Given the fear of litigation as well as trial by media and social media and of the rising problem of violence against doctors (41), it is not surprising that there is no consensus among pathologists about the appropriate approach.

In a retrospective study, it is not uncommon to unearth erroneous diagnoses made in the past. There are also obvious ethical concerns, which arise when one retrospectively learns of an error committed earlier by a colleague, or by oneself. How does one deal with such error that has happened in the recent past? Should one inform the patient of the error? What are the legal implications of such a disclosure? What does one do if one realises that a particular colleague is responsible for a significantly large number of errors? These are no easy answers to these difficult questions (42).

\section{Non-maleficence and screening for disease}

Screening for disease has the potential to benefit some, but also the possibility of causing harm to some. Physicians inviting the public for screening tests should communicate the benefits as well as the risks of the procedures. Similarly, the annual health check - with a substantial laboratory component - needs a judicious approach. Recent evidence suggests that the routine health check makes little difference to mortality from cancer and cardiovascular disease $(43,44)$. Yet, doing away entirely with all health checks would be erroneous. The selective use of clinically indicated investigations, rather than uniform panels of tests for all may be the most appropriate step.

\section{Non-maleficence and overdiagnosis}

Unexpected ethical issues have also surfaced recently. The easy availability of ultrasound has led to a marked increase in diagnosis of small thyroid nodules with the result that there has been a veritable "epidemic" of papillary carcinoma of the thyroid. How many are incidentalomas which would have been asymptomatic, and ideally should have never been detected? Schnadig (45) advises that the concept of overdiagnosis must be included in pathology education as well as to the public and that limits must be set, by consensus with the physicians concerned, for screening by ultrasound and fine needle aspiration as well as mutation analysis.

Similarly, genetic testing also often yields unexpected findings and raises challenging ethical issues pertaining to autonomy and consent (46).

\section{Other issues}

Over investigation also leads to unnecessary expenditure for the patient or for the institution. Wastage of resources is an ethical issue and must be addressed by pathologists (3).

Finally, while the concept of "harm" or non-maleficence usually refers to the living, it is vital that we offer the same principles of respect to the body, while we deal with the dead at autopsies.

\section{Justice}

Justice is fairness and equality and fair distribution of resources in society
Laboratory personnel should treat all patients fairly and without discrimination. They have duties towards the patient as well as towards society (4). Distributive justice in the allocation of scarce resources is achieved by preventing unnecessary laboratory investigations, thus preventing wastage of manpower, reagents, cost and time. There should be equitable access to laboratory investigations for all patient groups. The approach will, of course vary vastly between countries with Universal health coverage and those where private healthcare is common. Ideally, all laboratory tests, should be available without discrimination either because of race or gender or cultural/socioeconomic/ personal beliefs. The reality is different. However, there should be a balance between individual good and societal common good. Occasionally, laboratory staff are pressurised to deviate from the routine workflow to favour "very important persons". Such situations should be handled in a balanced manner so that no harm is caused to other patients and there is no violation of justice as far as healthcare resources are concerned (47).

Equally difficult are situations where clinical colleagues request unwarranted investigations, possibly due to a lack of understanding of the complexity of the test and its attendant merits and demerits, or as a part of defensive medicine (48). While this is a difficult problem, attempts must be made to communicate with and educate the clinician. Over investigating one patient may result in another patient being under investigated (3).

We end with an oath for pathologists, based partly on an earlier oath, that one of us had co-authored (49).

\section{A pathologist's oath}

I promise to use my knowledge of medicine and of pathology to diagnose the patient's condition, using my training and whatever means I have in the laboratory. I shall, however, not perform unwarranted tests.

Because one's life is one's most valuable possession, and because a patient has chosen to trust me with his or her life, I shall respect that trust and shall be grateful to the patient for putting his or her trust in me. Because trust is a two way affair, I would also expect the patient to trust me as I endeavour to care and heal.

I shall follow the laws of the land. Where guidelines are in direct conflict with my personal beliefs, I shall guide the patient appropriately, even if it means referring the patient to another physician.

I shall respect the patient's right to confidentiality and autonomy, and shall not discuss his or her condition with anyone unrelated to his treatment protocol, without his permission.

I shall always endeavour to prevent any kind of harm, whether physical or mental or financial and thus practise non-maleficence.

The patient's welfare takes priority and I shall, thus, practise 
the Hippocratic ideal of Primum non nocere.

I shall be scrupulously honest in my dealings with my colleagues. I know that some colleagues can be difficult to get along with; conversely, it is possible that, at least on occasion, I may be unreasonable. Either way, I shall never let my personal likes and dislikes come in the way of patient management.

I shall remain true to my chosen profession of medicine and pathology in particular. I shall not demean myself by offering cuts or kickbacks to anyone. I shall also not accept commissions or freebies or company junkets or other arrangements that might compromise my opinion of people or companies of any kind, which could bias my objective thinking and clinical practice.

I understand that these are my personal beliefs and may not be shared, in full, by every colleague or organisation that I may be associated with. Thus, I shall attempt to balance the best interests of all parties involved, with patient safety and care being the prime consideration.

I shall keep up with the advances in medical literature and try my best to use the knowledge in a dispassionate and scientific manner. I shall evaluate carefully, all new tests before accepting them as reliable and useful. Thus, I shall not blindly recommend "routine" health checks.

I shall attempt to spread relevant medical knowledge to the community in whatever manner possible, either by writing in the lay press or at lectures.

I shall try my best to work in as scientific and ethical a manner as possible. I shall take care not to waste precious resources, and shall continually attempt to reduce costs, without, in anyway, compromising on patient safety.

I take my work seriously, but not myself. Because laughter is the best medicine, I shall try to see good humour in situations that warrant it.

I shall treat my technologists as colleagues and try to raise their awareness and understanding of their science.

Were I to perform an autopsy, I would treat the cadaver with the same respect befitting a living person.

I am aware that error of one kind or the other, including erroneous diagnosis, is inevitable in my field; I shall take the utmost care to reduce the possibility of error. When I am not certain of a diagnosis, I shall attempt to offer a clinically useful differential diagnosis. Further, when indicated, I shall recommend that the patient seek an expert opinion on the case. Depending on the specific circumstances, I shall help the patient get a second opinion.

I shall not venture into areas that I am not qualified to practise. However, given my basic background as a physician, I shall endeavour to offer my opinion, when needed, on matters beyond pathology.

Because medicine consists of life-long learning, I expect to be in a position where I will benefit from the learning of others. Similarly, I hope to be able to learn from the vast experience of my colleagues.

I believe that research is an important component of my role as a physician-pathologist. I shall attempt to investigate and find the answers to questions that are of importance, without wasting resources or putting patient safety in jeopardy. I shall concentrate on diseases of local, regional and national importance.

I shall use the most appropriate journal to spread the fruit of my research. I shall not fall prey to predatory journals by either publishing in them or by refereeing their articles.

I shall not manipulate data or plagiarise or indulge in other unethical publication practices. I shall do my best to encourage my younger colleagues and friends, including those from other departments; this, I shall do, by allowing them to make the effort and earn first author position, where feasible. Because I believe in the circle of life, I would expect them to do the same subsequently with their younger colleagues.

I take this oath voluntarily, not because it is mandatory or fashionable or politically correct, but because I truly believe in it.

\section{Conflict of interest: None declared.}

\section{Acknowledgements: None.}

\section{References}

1. Rohr UP, Binder C, Dieterle T, Giusti F, Messina CGM, Toerien E, Moch $\mathrm{H}$, Schaefer $\mathrm{HH}$. The value of in-vitro diagnostic testing in medical practice: A status report. PLoS One. 2016; 11: e0149856.

2. Beauchamp TL, Childress JF. Principles of biomedical ethics. New York: Oxford University Press; 2008.

3. Baron DN. Ethical issues and clinical pathology. J Clin Pathol. 1993 May; 46(5):385-7.

4. McQueen MJ. Ethics and laboratory medicine. Clin Chem. 1990 Aug; 36(8 Pt 1):1404-7.

5. Wijeratne N, Benatar SR. Ethical issues in laboratory medicine. J Clin Pathol. 2010 Feb;63(2):97-8.

6. Nyrhinen T, Leino-Kilpi $\mathrm{H}$. Ethics in the laboratory examination of patients. J Med Ethics 2000 Feb; 26(1):54-60.

7. Stempsey WE. The virtuous pathologist. An ethical basis for laboratory medicine. Am J Clin Pathol 1989 Jun; 91(6):730-8.

8. World Health Organization, Eastern Mediterranean Office. Ethical practice in laboratory medicine and forensic pathology. Alexandria, Egypt: WHO EMRO; 1999 [cited 2019 Dec 10]. Available from: http:// applications.emro.who.int/dsaf/dsa38.pdf

9. Consolidated Guidelines on HIV Testing Services: 5Cs: Consent, Confidentiality, Counselling, Correct Results and Connection 2015. Geneva: WHO; 2015 Jul [cited 2019 Dec 12]. Available from: https:// apps.who.int/iris/bitstream/handle/10665/179870/9789241508926_ eng.pdf? sequence $=1$ \&isAllowed $=y$

10. Drut R. Who is the owner of the slides, blocks and fixed tissues? Am J Surg Pathol. 2002 Feb; 26(2) : 274.

11. Epstein Jl, Kidwell R. Author's reply. Am J Surg Pathol. 2002 Feb, 26(2): 274.

12. Vaz M, Sridhar TS, Pai SA. The ethics of research on stored biological samples: Outcomes of a Workshop. Indian J Med Ethics 2016 Apr- 
Jun;1(2):118-22

13. Chinoy RF. Some ethical issues in histopathology. Issues Med Ethics 2000 Jan -Mar; 8(1):22-23.

14. Dry S. Who owns diagnostic tissue blocks? Lab Med. 2009 Feb, 40(2): 69-73.

15. Vaught JB, Lockhart N, Schneider JA.. Ethical, legal and policy issues: Dominating the biospecimen dissection. Cancer Epidemiol Biomarkers Prev. 2007 Dec,16(12): 2521-3.

16. Allen MJ, Powers ML, Gronowski KS, Gronowski AM. Human tissue ownership and use in research: What laboratorians and researchers should know. Clin Chem 2010 Nov,56(11): 1675-82.

17. Dry S, Grody WW, Papagni P. Stuck between a scalpel and a rock, or molecular pathology and legal-ethical issues in use of tissues for clinical care and research. Am J Clin Pathol. 2012 Mar; 137(3): 346-55.

18. Charo RA. Body of research- Ownership and use of human tissue. New Engl J Med. 2006; 355: 1517-1519.

19. van Diest PJ. No consent should be needed for using leftover body material for scientific purposes. For. BMJ. 2002 Sep 21;325 (7365):64851.

20. Savulescu J. No consent should be needed for using leftover body material for scientific purposes. Against. BMJ.2002; 325 (7365): 648-51.

21. Yassin R, Lockhart N, González del Riego M, Pitt K, Thomas JW, Weiss L, Compton C. Custodianship as an ethical framework for biospecimenbased research. Cancer Epidemiol Biomarkers Prev. 2010 Apr; 19(4): 1012-15.

22. Furness PN, Nicholson ML. Obtaining explicit consent for the use of archival tissue samples: practical issues. J Med Ethics 2004 Dec; 30(6): 561-4.

23. Lane $M$, Vercler $C J$. Is consent to autopsy necessary? Cartesian dualism in medicine and its limitations. AMA J Ethics 2016 Aug 1; 18(8):771-8.

24. Pai SA, Pandya SK. 'Living in the clouds of a vain illusion': The decline and fall of clinical autopsies. Natl Med J India. 2016 May; 29(3):125-8.

25. Bauchner $\mathrm{H}$. What have we learnt from the Alder Hey affair? That monitoring physicians' performance is necessary to ensure good practice. BMJ 2001Feb 10; 322(7282):309-10.

26. Kumar S. Medical confidentiality broken to stop marriage of man infected with HIV. Lancet 1998 Nov 28;3529(9142): 1764.

27. BMJ Author Hub. Patient consent and confidentiality. BMJ.com. date unknown [cited 2019 Jul 6]. Available from: https://authors.bmj.com/ policies/patient-consent-and-confidentiality/

28. Tranberg $\mathrm{H}$ A, Rous B A, Rashbass J. Legal and ethical issues in the use of anonymous images in pathology teaching and research. Histopathology 2003 Feb; 42(2): 104-9.

29. Crane GM, Gardner JM. Pathology image-sharing on social media: Recommendations for protecting privacy while motivating education AMA J Ethics. 2016 Aug 1; 18 (8): 817-25.

30. Pai SA. Medical journals - In the news and for the wrong reasons. Indian JMed Ethics. 2014 Jan-Mar; 11(1):7-9.

31. Moher D, Shamseer L, Cobey K, Lalu MM, Gallipeau J, Avey MT, et al.Stop this waste of people, animals and money. Nature.2017 Sep 6;549(7670):
23-5.

32. Pai SA. Laboratory tests: proper communication reduces error. Student BMJ. 2005; 13:397-400.

33. Hernandez JS. No pay, no play - The end of professional ethics in pathology. Arch Pathol Lab Med. 2011 Oct; 135: 1246-7.

34. Murphy WM. Ethical issues in anatomic pathology: are we going the way of the financial sector? Am J Surg Pathol 2003 Mar; 27(3):392-5.

35. Kohn LT, Corrigan JM, Donaldson MS (Institute of Medicine). To err is human: building a safer health system. Washington, DC: National Academy Press; 2000.

36. National Academies of Sciences, Engineering and Medicine. Improving diagnosis in health care. Washington, DC: National Academy Press; 2015.

37. Dintzis SM, Stetsenko GY, Sitlani CM, Gronowski AM, Astion ML Gallagher TH. Communicating pathology and laboratory errors: Anatomic pathologists' and laboratory medical directors' attitudes and experiences. Am J Clin Pathol. 2011 May; 135(5): 760-5.

38. Perkins IU. Error disclosure in pathology and laboratory medicine: $\mathrm{A}$ review of the literature. AMA J Ethics. 2016 Aug 1, 18(8): 809-16.

39. Dintzis SM, Clennon EK, Prouty CD, Reich LM, Elmore JG, Gallagher TH. Pathologists's perspectives on disclosing harmful pathology error. Arch Pathol Lab Med. 2017 Jun; 141(6): 841-5.

40. Heher YK, Dintzis SM. Disclosure of harmful medical error to patients: A review with recommendations for pathologists. Adv Anat Pathol. 2018 Mar; 25(2): 124-30

41. Pai SA. Violence against doctors on the increase in India. Natl Med J India. 2015 Jul-Aug; 28 (4):214-15

42. Pai SA, Kulkarni JD. Spectrum of lymph node pathology: Inadequate data, challenging issues. Indian J Pathol Microbiol. 2014 Jul-Sep; 57(3) :522-3.

43. Krogsbøll LT, Jørgensen KJ, Larsen CG, Gotzsche PC. General health checks in adults for reducing morbidity and mortality from disease. Cochrane Database Syst Rev. 2012 Oct 7; 10,: CD009009. DOI: $10.1002 / 14651858$.

44. Honnekeri B, Vyas A, Lokhandwala D, Vaishnav A, Vaishnav A, Singhal $M$, et al. Routine health check-ups: A boon or a burden? Natl Med J India. 2016 Jan-Feb; 29 (1):18 -21.

45. Schnadig VJ. Overdiagnosis of thyroid cancer - Is this not an ethical issue for pathologists as well as radiologists and clinicians? Arch Pathol Lab Med. 2018 Sep, 142(9):1018-20.

46. Wouters RHP, Cornelis C, Newsome AJ, Bunnick EM, Bredenoord AL. Scanning the body, sequencing the genome: Dealing with unsolicited findings. Bioethics. 2017 Nov; 31(9): 1-9.

47. Sheffield V, Smith LB. Requests for VIP treatment in pathology: Implications for social justice and systems-based practice. AMA J Ethics. 2016 Aug 1; 18(8):786-92.

48. Magers MJ, Cinti SK. Ordering stains that aren't indicated. AMA J Ethics, 2016 Aug 1; 18(8):793-9.

49. Pai SA, Pandya SK. A revised Hippocratic oath for Indian medical students. Natl Med J India. 2010 Nov-Dec; 23(6): 360-1. 